\title{
Diabetes and pruritus
}

\author{
PARASTOO BABAKINEJAD,1 SHERNAZ WALTON²
}

\begin{abstract}
Pruritus is often reported to be associated with diabetes mellitus although this remains controversial. Careful historytaking and examination are key to establishing the cause of itching in a patient with diabetes after excluding local cutaneous disease or an underlying lymphoma. Options for management of this distressing condition include emollients, topical antipruritic agents (e.g. calamine, menthol, capsaicin, corticosteroids, calcineurin inhibitors or local anaesthetics), systemic antipruritic agents (e.g. $\mathrm{H}_{1}$ antihistamines, doxepin and gabapentin), broad-band or narrowband ultraviolet B phototherapy and psychological therapies.

Br J Diabetes 2016;16:154-155
\end{abstract}

Key words: pruritus, diabetes, neuropathy, autonomic dysfunction, excoriations, lichenification, candidiasis, emollients, antipruritics, ultraviolet therapy

\section{Introduction}

Chronic pruritus is a common symptom of a range of skin and systemic diseases. Studies looking at the prevalence of pruritus are limited. One study has shown $8 \%$ prevalence in an adult population in Norway. ${ }^{1}$ A cross-sectional study in Germany showed a high prevalence (36.2\%) of pruritus in 334 patients attending to see dermatologists over one week. The majority of these patients (87.6\%) had chronic pruritus. ${ }^{2}$

Pruritus is often believed to be a common manifestation of diabetes. It has also been reported to be secondary to diabetic neuropathy, metabolic derangements associated with renal failure, or autonomic dysfunction resulting in anhidrosis, xerosis, pruritus ani and pruritus vulvae. ${ }^{3} \mathrm{Al}$-Mutairi et al looked at the prevalence of cutaneous manifestations in 106 patients with diabetes mellitus: pruritus was shown to be the second most common cutaneous manifestation, with $49 \%$ of patients affected. ${ }^{4} \mathrm{~A}$ study in elderly subjects showed diabetes to be a statistically significant predictor

Department of Dermatology, County Durham and Darlington NHS Foundation Trust, UK

2 Department of Dermatology, Hull and East Yorkshire Hospitals NHS Trust and Hull York Medical School, Hull, UK

Address for correspondence: Professor Shernaz Walton Department of Dermatology, Hull Royal Infirmary, Anlaby Road, Hull HU3 2JZ, UK

Tel: $+44(0) 1482816623$

E-mail: shernaz.walton@hey.nhs.uk

http://dx.doi.org/10.15277/bjd.2016.095
Figure 1. Excoriations in a diabetic patient with pruritus

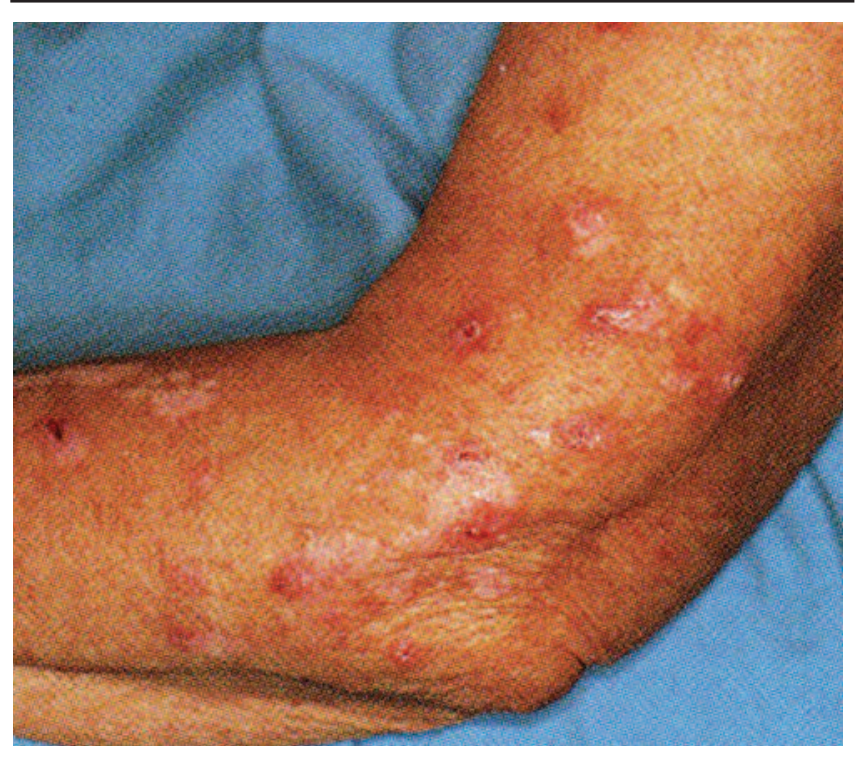

of pruritus. ${ }^{5}$ In contrast, one study showed that generalised pruritus of unknown cause was especially common in people with diabetes (8/300 patients), but pruritus vulvae was significantly more common in women with diabetes (18.4\%) compared with 100 non-diabetic controls (5.6\%) and was strongly associated with poor diabetic control. ${ }^{6}$

\section{Diagnosis, causes and clinical findings}

Pruritus can be the result of an underlying dermatological condition, systemic disease, an adverse effect of drug treatment, or neuropathic or psychiatric diseases. ${ }^{7}$ Itching due to diabetes is rare, despite diabetes often being cited as a cause of pruritus (see above). ${ }^{8}$ Pruritus can be multifactorial or sometimes no underlying cause is identified. ${ }^{7}$ A thorough history and examination is key to identifying the cause.

It is important to differentiate between both chronic and acute pruritus and between generalised and localised pruritus; generalised pruritus may be a symptom of underlying systemic disease whereas localised pruritus is often due to local cutaneous disease. ${ }^{7}$ The initial focus of the examination should be aimed at excluding an underlying cutaneous disease such as atopic dermatitis, psoriasis, contact dermatitis, bullous pemphigoid, urticaria or infestations. In pruritus of unknown cause, examination of the lymph nodes, liver and spleen is recommended to exclude systemic disease such as 
lymphoma. Clinical findings in patients with no underlying dermatological condition commonly include excoriations and lichenification without primary skin lesions (Figure 1). ${ }^{3}$

In patients with generalised pruritus, pruritic screen including full blood count, renal function, liver function, thyroid function tests, blood glucose and serum ferritin are recommended to exclude systemic causes. ${ }^{7}$ Ko et al studied the link between glycaemic control and generalised pruritus in 385 patients with type 2 diabetes. ${ }^{9}$ A significant number of patients (27.5\%) suffered from pruritus resulting in sleep disturbance. Higher postprandial glucose levels were shown to result in a higher probability of having generalised pruritus (odds ratio $1.41,95 \% \mathrm{Cl} 1.05$ to $1.90, \mathrm{p}=0.02$ ). ${ }^{9}$ Another study showed that pruritus was independently associated with $\mathrm{HbA}_{1 \mathrm{c}}$ in both diabetic and non-diabetic patients undergoing haemodialysis, although diabetic patients experienced more severe pruritus than non-diabetic patients as demonstrated by a visual analogue scale pruritus score $(4.7 \pm 2.8$ vs. $3.0 \pm 1.0, p=0.015) .{ }^{10}$ The authors proposed that neuropathy could play a part in explaining pruritus in patients undergoing haemodialysis as this is common in both uraemic and diabetic patients. ${ }^{10}$

Localised severe pruritus of the scalp without clinical features of underlying cutaneous diseases has been reported in patients with diabetes. ${ }^{11}$ Anogenital pruritus may also occur more frequently in diabetic patients due to mucocutaneous candidiasis. ${ }^{12}$

\section{Management}

Optimal management of the underlying systemic disease is the mainstay of treatment. For chronic generalised pruritus, treatment options include emollients, topical antipruritic agents such as calamine, menthol, capsaicin, corticosteroids, calcineurin inhibitors, local anaesthetics and systemic antipruritic agents such as $\mathrm{H}_{1}$ antihistamines, doxepin and gabapentin. Broad-band or narrowband ultraviolet B phototherapy can be used to treat generalised chronic pruritus of any cause. Psychological therapies may help relieve pruritus and improve the quality of life. ${ }^{7}$

\section{Conflict of interest None.}

\section{References}

1. Yosipovitch G, Patel TS. Pathophysiology and clinical aspects of pruritus. In: Goldsmith LA, Katz SI, Gilchrest BA, Paller AS, Leffell DJ and Wolff K (eds). Fitzpatrick's Dermatology in General Medicine, 8th edition. The

\section{Key messages}

- Careful history taking and examination are key to establishing the cause of itching in a patient with diabetes after excluding local cutaneous disease or an underlying lymphoma

- Itching due to diabetes is rare, despite diabetes often being cited as a cause of pruritus

- Anogenital pruritus may occur more frequently in diabetic patients due to mucocutaneous candidiasis

McGraw-Hill Companies, 2012, 1147-57

2. Kopyciok ME, Ständer HF, Osada N, Steinke S, Ständer S. Prevalence and characteristics of pruritus: a one-week cross-sectional study in a German dermatology practice. Acta Derm Venereol 2016;96:50-5. http://dx.doi.org/10.2340/00015555-2166.

3. Etter L, Myers SA. Pruritus in systemic disease: mechanisms and management. Dermatol Clin 2002;20:459-72. http://dx.doi.org/10.1016/\$0733-8635(02)00011-6

4. Al-Mutairi N, Zaki A, Sharma AK, Al Sheltawi M. Cutaneous manifestations of diabetes mellitus. Med Princ Pract 2006;15:427-30. http://dx.doi.org/10.1159/000095488

5. Teoh YL. Pruritus in the elderly and its impact on quality of life. J Am Acad Dermatol 2012;66(4 Suppl 1):AB11.

6. Neilly JB. Pruritus in diabetes mellitus: investigation of prevalence and correlation with diabetes control. Diabetes Care 1986;9:273-5. http://dx.doi.org/10.2337/diacare.9.3.273

7. Weisshaar E, Fleischer Jr AB, Bernhard JD, Cropley TG. Pruritus and dysesthesia. In: Bolognia JL, Jorizzo JL, Schaffer JV (eds). Dermatology, 3rd edition. Elsevier, 2012, 111-20.

8. Zaidi Z, Walton S. Pruritus. In: Zaidi Z, Walton S (eds). A Manual of Dermatology, 2nd edition. Jaypee Brothers Medical Publishers, 2015, 469-79. http://dx.doi.org/10.5005/jp/books/12564_23

9. Ko MJ, Chiu HC, Jee SH, Hu FC, Tseng CH. Postprandial blood glucose is associated with generalized pruritus in patients with type 2 diabetes. Eur $J$ Dermatol 2013;23:688-93. http://dx.doi.org/10.1684/ejd.2013.2100

10. Afsar $B$, Elsurer Afsar R. HbA1c is related with uremic pruritus in diabetic and nondiabetic hemodialysis patients. Ren Fail 2012;34:1264-9. http://dx.doi.org/10.3109/0886022X.2011.560401

11. Scribner M. Diabetes and pruritus of scalp. JAMA 1977;237:155 http://dx.doi.org/10.1001/jama.1977.03270420027007

12. Greaves MW. Itching in systemic disease. In: Burns DA, Breathnach SM Champion RH, Burton JL (eds). Rook's Textbook of Dermatology, 8th edition. Blackwell Publishing, 2010, 21.11. 